\title{
ABC transporters in Mycoplasma hyopneumoniae and Mycoplasma synoviae: Insights into evolution and pathogenicity
}

\author{
Marisa Fabiana Nicolás ${ }^{1}$, Fernando Gomes Barcellos ${ }^{2}$, Pablo Nehab Hess ${ }^{1}$ and Mariangela Hungria ${ }^{2}$ \\ ${ }^{1}$ Laboratório Nacional de Computação Cientifica, Petrópolis, RJ, Brazil. \\ ${ }^{2}$ Embrapa Soja, Londrina, PR, Brazil.
}

\begin{abstract}
$A B C$ transporters represent one of the largest superfamilies of active membrane transport proteins (MTPS) with a highly conserved ATPase domain that binds and hydrolyzes ATP, supplying energy for the uptake of a variety of nutrients and for the extrusion of drugs and metabolic wastes. The complete genomes of a non-pathogenic $(\mathrm{J})$ and pathogenic (7448) strain of Mycoplasma hyopneumoniae, as well as of a pathogenic (53) strain of Mycoplasma synoviae have been recently sequenced. A detailed study revealed a high percentage of CDSs encoding MTPs in $M$. hyopneumoniae strains J (13.4\%), 7448 (13.8\%), and in M. synoviae $53(11.2 \%)$, and the ABC systems represented from 85.0 to $88.6 \%$ of those CDSs. Uptake systems are mainly involved in cell nutrition and some might be associated with virulence. Exporter systems include both drug and multidrug resistant systems (MDR), which may represent mechanisms of resistance to toxic molecules. No relation was found between the phylogeny of the ATPase domains and the lifestyle or pathogenicity of Mycoplasma, but several proteins, potentially useful as targets for the control of infections, were identified.
\end{abstract}

Key words: ABC transporters, bioinformatics, genomes of microorganisms, membrane transport proteins, Mycoplasma, phylogeny of prokaryotes.

Received: April 4, 2006; Accepted: October 5, 2006.

\section{Introduction}

ATP-binding cassette systems, also known as $\mathrm{ABC}$ transporters or traffic ATPases, represent one of the largest superfamilies of active membrane transport proteins (MTPs). These transporters contain a highly conserved ATPase domain, the ABC (ATP-binding domain or nucleotide-binding domain, NBD), which binds and hydrolyzes ATP, supplying energy for the uptake of a variety of nutrients and for the extrusion of drugs and metabolic wastes from cells and organelles (Schneider and Hunke, 1998; Braibant et al., 2000; Dassa and Bouige, 2001; Higgins, 2001; Davidson and Chen, 2004; Garmory and Titball, 2004; Ren and Paulsen, 2005). In bacteria, the number of $\mathrm{ABC}$ transporters correlates with the genome size as well as with the physiological niche in which they live, suggesting that the proteins are likely to be necessary for growth, survival, or competitiveness among microbes for nutrients in different ecological niches (Harland et al., 2005; Ren and Paulsen, 2005). An increased interest in $\mathrm{ABC}$ transporters

Send correspondence to Mariangela Hungria. Embrapa Soja, Caixa Postal 231, 86001-970 Londrina, Paraná, Brazil. E-mail: hungria@cnpso.embrapa.br. can be explained by their potential as targets for the development of antitumor agents, antibacterial vaccines and antimicrobials (Garmory and Titball, 2004).

The transporter classification system (TC-DB) at the University of California - San Diego (Tran et al., 2003) classifies the ATP-binding Cassette (ABC) Superfamily (TC\# 3.A.1) as importers and exporters (Saurin et al., 1999; Saier, 2000; Dassa and Bouige, 2001; Garmory and Titball, 2004), and each type of ABC transporter has different protein structures (Dassa and Bouige, 2001). The basic unit of an $\mathrm{ABC}$ transporter (Figure 1) consists of four structural domains: two hydrophobic transmembrane domains (TMDs, or integral membrane domains, IMDs, or membrane-spanning domains, MSDs), and two hydrophilic cytoplasmic domains (Linton and Higgins, 1998). Importers usually have the four domains encoded by independent polypeptides (Figure 1a) and require an extracellular substrate-binding protein, but differences may be found among organisms. In Gram-negative bacteria the importers are usually associated with periplasmic substrate-binding proteins (PBP), whereas in Gram-positive bacteria and in Mycoplasma they are generally associated with surfaceanchored lipoproteins. Prokaryote exporters may have the four domains separated or fused in many ways 


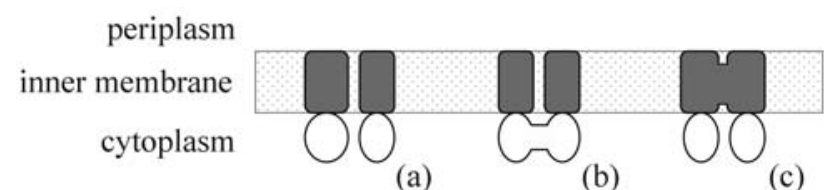

(a)

(b)

(c)

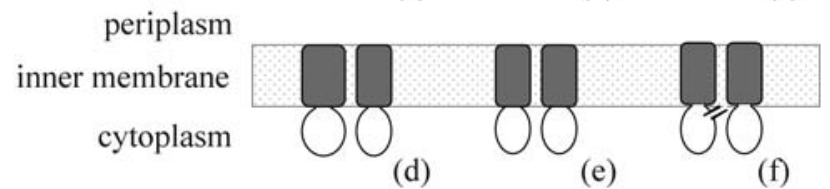

Figure 1 - Organization of $\mathrm{ABC}$ transporters. The typical $\mathrm{ABC}$ transporter has four domains, two membrane associated domains (IMDs, TMDs or SMD) and two ATP-binding domains (ABCs). a) In some transporters the four domains can be encoded as separate polypeptides (e.g. TC\# 3.A.1.5.1 OppABCDF of S. typhimurium). In other transporters the domains may be fused in a variety of configurations: b) fused ABCs (as in the ribose transporter TC\# 3.A.1.2.1 RbsABCD of E. coli); c) fused IMDs (as in the ferrichrome transport system TC\# 3.A.1.14.3 FhuBCD of $E$. coli); d) $\mathrm{ABC}$ fused to IMDs, with the active protein functioning as homodimer (as in the multidrug exporter TC\# 3.A.1.117.1 LmrA of Lactococcus lactis); e) one $\mathrm{ABC}$ fused to one IMD, with the other $\mathrm{ABC}$ and IMD as separate polypeptides (as in the YhiGHI of E. coli); f) all four domains fused into a single polypeptide, often found in eukaryotic $\mathrm{ABC}$ transporters.

(Figure 1d,e). Moreover, the transport complex system generally consists of an $\mathrm{ABC}$ exporter and of a protein belonging to the membrane fusion protein (MFP) family (TC\# 8.A.1).

The genus Mycoplasma belongs to the phylum Firmicutes, class Mollicutes (mollis, soft; cutis, skin, in Latin), order Mycoplasmatales, and family Mycoplasmatacea; bacteria within the genus lack cell walls and are bounded only by a plasma membrane (Holt et al., 1994; Razin et al., 1998). The mycoplasmas are one of the smallest and simplest prokaryotes capable of self-replication and leading an autonomous life. They are also of interest in studies trying to define the minimal genome requirements (Hutchison and Montague, 2002). The small genomes of Mycoplasma species are low in $\mathrm{G}+\mathrm{C}(\mathrm{Mol} \%, 23-40)$ and range from 580,070 bp (M. genitalium strain G-37, Fraser et al., 1995) to $1,358,633$ bp (M. penetrans strain HF-2, Sasaki et al., 2002). The current hypothesis is that Mycoplasma evolved from low $\mathrm{G}+\mathrm{C}$ Gram-positive bacteria, by reductive evolution, resulting in genome reduction, loss of cell wall and development of sterol requirement, followed again by genome reduction (Razin, 1985, 1992; Rocha and Blanchard, 2002).

The complete genomes of a non-pathogenic $(\mathrm{J}=$ ATCC 25934) and of a pathogenic (7448) strain of $M$. hyopneumoniae, this last one an infective agent of enzootic pneumonia in swine, as well as of the poultry pathogenic strain 53 of $M$. synoviae have been recently sequenced (Vasconcelos et al., 2005). Here we have investigated, in greater detail, the $\mathrm{ABC}$ transporters in those three genomes, in an effort to obtain more information about the evolution, lifestyle and pathogenicity of these species.

\section{Material and Methods}

Valid CDSs encoding ABC transporters of $M$. synoviae strain 53 and of $M$. hyopneumoniae strains $\mathrm{J}$ and 7448 were retrieved from the BRGENE, GENESUL and NCBI databases. Missing genes were confirmed through NCBI tblastn program using known Mycoplasma proteins as queries against the three genomes. The InterProScan and ScanProsite online programs were also used to identify the ABC ATP-binding and transmembrane domains. Online topology prediction programs, such as DAS and Tmpred were applied to recognize transmembrane regions. The ABCISSE database was used to validate the uptake and efflux systems. The transporter numbers (TC\#) were defined using TC-DB database nomenclature.

For the phylogenetic analysis, 14 ATP-binding domains from $\mathrm{ABC}$ proteins presented in all three genomes were retrieved from the BRGENE, GENESUL and NCBI databases. The least conserved segments of these sequences were eliminated and multiple sequence alignments were performed with CLUSTAL W version 1.83 (Thompson et al., 1994). Phylogenetic trees were built using MEGA version 3.1 (Kumar et al., 2004) with default parameters and the JTT substitution matrix (Jones et al., 1992). The pairwise deletion criterion was used in order to maximize the number of sites compared between sequences. The bootstrap test (Felsenstein, 1985) was used to calculate the statistical support for individual nodes, with 1,000 replicates and consensus cut-off value of $60 \%$.

\section{Results and Discussion}

\section{Overview of $A B C$ transporters in Mycoplamas}

To date, in addition to the three genomes from this study, eight complete mycoplasma genomes have been sequenced: M. genitalium G-37 (Fraser et al., 1995), M. pneumoniae M129 (Himmelreich et al., 1996), M. pulmonis UAB CTIP (Chambaud et al., 2001), M. penetrans HF-2 (Sasaki et al., 2002), M. gallisepticum R (Papazisi et al., 2003), M. mobile $163 \mathrm{~K}$ (Jaffe et al., 2004), M. mycoides subsp. mycoides PG1T (Westberg et al., 2004), M. hyopneumoniae 232 (Minion et al., 2004) and $M$. capricolum subsp. capricolum ATCC 27343 (unpublished data). In all but one genome (32.4\% in M. mobile strain 163 $\mathrm{K}$, Jaffe et al., 2004), ATP-dependent transporters represented $50 \%$ or more of all membrane transport proteins, and ABC proteins represented from 58.8\% (M. mycoides subsp. mycoides PG1T, Westberg et al., 2004) to $91.7 \%$ (M. mobile strain $163 \mathrm{~K}$ ) of all ATP-dependent proteins.

In relation to $M$. synoviae strain 53 and $M$. hyopneumoniae strains $\mathrm{J}$ and $7448,11.2 \%, 13.4 \%$ and $13.8 \%$ of the valid CDSs were transporters, respectively, and $\mathrm{ABC}$ systems represented from $85.0 \%$ to $88.6 \%$ of all transporters CDSs (Table 1). The number of CDSs in these three genomes is higher than in other mycoplasmas se- 
Table 1 - General transporter CDSs present in the $M$. synoviae strain 53 (MS) and M. hyopneumoniae strains J (MHJ) and 7448 (MHP) genomes ${ }^{1}$.

\begin{tabular}{lccc}
\hline CDS & (MS) & (MHJ) & (MHP) \\
\hline Transporter & 88 & 107 & 109 \\
ABC transporter ${ }^{(1)}$ & 78 & 91 & 94 \\
Valid & 694 & 679 & 681 \\
$\begin{array}{l}\text { Transporter in valid } \\
\text { CDSs (\%) }\end{array}$ & 12.7 & 15.8 & 16.0 \\
$\begin{array}{l}\text { ABC transporter in valid } \\
\text { CDSs (\%) }\end{array}$ & 11.2 & 13.4 & 13.8 \\
$\begin{array}{l}\text { ABC transporter in trans- } \\
\text { porter CDSs (\%) }\end{array}$ & 88.6 & 85.0 & 86.2 \\
\hline
\end{tabular}

${ }^{1}$ In accordance with Vasconcelos et al. (2005), but including peripheral membrane proteins of each $\mathrm{ABC}$ complex.

quenced. This is due first to the fact that peripheral membrane proteins of each $\mathrm{ABC}$ complex were also considered, and second because we searched for the proteins by using a very careful manual procedure, since, as pointed out by Ren et al. (2004), it is often difficult to detect these proteins through current primary annotation due to the presence of multiple transporter gene paralogs and the complexity of the ABC family.

\section{Uptake systems}

ABC uptake systems are absent in eukaryotes, probably because their function was incorporated into other organelles (Ren and Paulsen, 2005). The comparison of several prokaryotes has indicated that the primary role of $\mathrm{ABC}$ uptake systems is the acquisition of nutrients, therefore a greater diversity of transporter types might allow the utilization of a broad range of substrates (ions, amino acids, carbohydrates, peptides, vitamins, polyamines, sulfate, metals, chelators, etc.) (Ren and Paulsen, 2005). Nine types of $\mathrm{ABC}$ transporters related to nutrients uptake were found in all three mycoplasma genomes, sharing structures similar to Gram-positive bacterial systems.

The ABC proteins capable of mediating the uptake of sugar and other carbohydrates are included in two families, which are designated as the carbohydrate uptake transporters 1 and 2 (CUT1 or TC\# 3.A.1.1 and CUT2 or TC\# 3.A.1.2). In general, members of CUT1 can transport diverse di- and oligosaccharides, glycerol, glycerol-phosphate and polyols, while CUT2 transporters can only transport monosaccharides (Schneider, 2001); members of both families are found in the three mycoplasmas (Table 2).

Uptake of glycerol by mycoplasmas can take place by the active system specified by GtsABC. In M. synoviae, three homologous genes encoding two transmembrane components (MS0385, MS0386) and one ATP-binding protein (MS0384) compose this ABC transporter, and activity may be mediated by the predicted lipoprotein $\mathrm{B}$ (MS0387). The genomic region shows similarity (50-60\%) with operon gts $\mathrm{ACB}$ and the $\operatorname{lp} p \mathrm{~B}$ gene of $M$. mycoides subsp. mycoides. Additionally, there is an overlap of all three CDSs encoding the $\mathrm{ABC}$ transporter, and it should be noted that analogous loci found in both $M$. mycoides subsp mycoides and $M$. genitalium are also composed of three overlapping CDSs. The three components of this ABC system were also found in both the $M$. hyopneumoniae pathogenic strain 7448 (MHP0369, MHP0370 and MHP0371) and the non-pathogenic strain J (MHJ0375, MHJ0376 and MHJ0377). The predicted lipoprotein B was identified in M. hyopneumoniae strain $\mathrm{J}$ (MHJ0374), whereas in the pathogenic strain 7448 other lipoproteins might function in combination with the ABC glycerol transporter (MHP0366, MHP0367 or MHP0368). Vilei and Frey (2001) assumed that the phosphate group sequestered from the ABC transporter GtsA, GtsB and GtsC could be transferred to glycerol (glycerol-3-phosphate, G3P) during the uptake process in $M$. mycoides subsp mycoides. CDSs encoding glycerol kinase $(\mathrm{glpK})$ have been identified in $M$. hyopneumoniae strains $\mathrm{J}$ and 7448 (MHJ0355 and MHP0359), and the only genome where $g l p \mathrm{~K}$ gene was not found was that of $M$. synoviae strain 53. In the cytoplasm, G3P might be used as substrate by glycerol-3-phosphate dehydrogenase (MHJ0588 and MHP0588), accompanied by massive release of hydrogen peroxide $\left(\mathrm{H}_{2} \mathrm{O}_{2}\right)$ (Vilei and Frey, 2001). It has been suggested that the production of $\mathrm{H}_{2} \mathrm{O}_{2}$ might be involved in the pathogenicity by damaging the host cells (Miles et al., 1991; Rice et al., 2001). Consequently, highly efficient glycerol systems allowing the production of $\mathrm{H}_{2} \mathrm{O}_{2}$ might represent a virulence attribute of those mycoplasmas. However, although the genes were present in both the pathogenic and non-pathogenic strains of M.hyopneumoniae, differences could reside in gene expression, which could be elucidated by simple biochemical assays to evaluate the production of $\mathrm{H}_{2} \mathrm{O}_{2}$ in the presence of glycerol (Rice et al., 2001).

Another member of the CUT1 family detected only in M. synoviae genome was the multiple sugar porter (MS0102, MS0103, MS0104 and MS0105), showing similarity (53-70\%) with M. pulmononis. This system is homologous to msm of Streptococcus mutans, which is responsible for the transport and utilization of raffinose, melibiose and isomaltotrioses and may be transcribed as a single operon (McLaughlin and Ferretti, 1996). The region upstream of MS0105 includes two CDSs for alpha-amylase (MS0108) and maltose/threhalose hydrolase (MS0107), thus suggesting a role in starch-degradation and sugar transport (Sahm et al., 1996).

A remarkable $\mathrm{ABC}$ uptake system annotated in the three mycoplasmas is the oligopeptide transporter OppABCDF, which has been well characterized in Salmonella typhimurium and Escherichia coli (Table 2). It is known that the transport of peptides is not only related to cell nutrition, but also to several signaling processes (Detmers et al., 2001). Recently, Hopfe and Henrich (2004) demonstrated in $M$. hominis that OppA, the substrate- 
Table 2 - Description of CDSs related to ABC importers (uptake systems) in the M. synoviae strain 53 (MS) and M. hyopneumoniae strains J (MHJ) and 7448 (MHP) genomes.

\begin{tabular}{|c|c|c|c|c|}
\hline Substrate & TC\# Description & (MS) & $(\mathrm{MHJ})$ & (MHP) \\
\hline $\begin{array}{l}\text { Carbohydrate } \\
\text { Glycerol }\end{array}$ & $\begin{array}{l}\text { 3.A.1.1.- (CUT1) Glycerol up- } \\
\text { take transporter (homolog to } \\
\text { GtsABC, LppB of } M \text {. } \\
\text { mycoides subsp. mycoides SC) }\end{array}$ & $\begin{array}{c}\text { MS0383 [C] }{ }^{1} \\
\text { MS0384 [M] } \\
\text { MS0385[M] } \\
\text { MS0386 [SB }]^{3} \\
\text { MS0329[SB] } \\
\text { MS0330 [C] MS0331 [M] } \\
\text { MS0332 [M] }\end{array}$ & $\begin{array}{l}\text { MHJ0374 [SB] } \\
\text { MHJ0375 [C] } \\
\text { MHJ0376 [M] } \\
\text { MHJ0377 [M] } \\
\text { MHJ0364 [SB] } \\
\text { MHJ0365 [C] } \\
\text { MHJ0366 [M] } \\
\text { MHJ0367 [M] }\end{array}$ & $\begin{array}{l}\text { MHP0366 [SB] } \\
\text { MHP0367 [SB] } \\
\text { MHP0368 [SB] } \\
\text { MHP0369 [C] } \\
\text { MHP0370 [M] } \\
\text { MHP0371 [M] } \\
\text { MHP0379 [C] } \\
\text { MHP0380 [M] } \\
\text { MHP0381 [M] }\end{array}$ \\
\hline $\begin{array}{l}\text { Carbohydrate multiple } \\
\text { sugar }\end{array}$ & $\begin{array}{l}\text { 3.A.1.1.2 (CUT1) } \\
\text { Multiple sugar (raffinose/ } \\
\text { melibiose/somaltotrioses) por- } \\
\text { ter (homolog to MsmEFGK of } \\
\text { S. mutans) }\end{array}$ & $\begin{array}{c}\text { MS0102 [C] } \\
\text { MS0103 [M] MS0104 [M] } \\
\text { MS0105 [SB] }\end{array}$ & $\mathrm{NF}^{5}$ & $\mathrm{NF}$ \\
\hline $\begin{array}{l}\text { Carbohydrate } \\
\text { Galactose Glucose } \\
\text { Ribose } \\
\text { Xylose }\end{array}$ & $\begin{array}{l}\text { 3.A.1.2.- (CUT2) } \\
\text { Galactose/Glucose/Ribose im- } \\
\text { porter }\end{array}$ & $\begin{array}{c}\text { MS0136 [SA }]^{4} \\
\text { MS0137 [C] } \\
\text { MS0138 [M] MS0139[M] }\end{array}$ & $\begin{array}{c}\text { MHJ0225 [C] } \\
\text { MHJ0226 [M] } \\
\text { MHJ0227 [SB] } \\
\text { MHJ0606 [SA }{ }^{4} \\
\text { MHJ0607 [C] } \\
\text { MHJ0608 [M] } \\
\text { MHJ0609 [M] } \\
\text { MHJ0511 [SA }{ }^{4} \\
\text { MHJ0512 [C] } \\
\text { MHJ0513 [M] }\end{array}$ & $\begin{array}{c}\text { MHP0231 [C] } \\
\text { MHP0233 [M] } \\
\text { MHP0234 [SB] } \\
\text { MHP0605 [C] } \\
\text { MHP0606 [M] } \\
\text { MHP0607 [M] } \\
\text { MHP0604 [SA }]^{4}\end{array}$ \\
\hline $\begin{array}{l}\text { Peptide } \\
\text { Oligopeptide }\end{array}$ & $\begin{array}{l}\text { 3.A.1.5.1. } \\
\text { Oligopeptide uptake importer } \\
\text { (homolog to OppABCDF of } \\
\text { S.typhimurium) }\end{array}$ & $\begin{array}{c}\text { MS0190 [SB }]^{6} \\
\text { MS0184 [M] MS0185 [M] } \\
\text { MS0186 [C] } \\
\text { MS0187 [C] } \\
\text { MS0349 [SB] } \\
\text { MS0348 [M] MS0347 [M] } \\
\text { MS0346 [C] } \\
\text { MS0345 [C] }\end{array}$ & $\begin{array}{c}\text { MHJ0207 }[\mathrm{SB}]^{6} \\
\text { MHJ0208 }[\mathrm{M}] \text { MHJ0209 [M] } \\
\text { MHJ0210[C] MHJ0211 [C] } \\
\text { MHJ0502 [SB] } \\
\text { MHJ0501 [M] MHJ0500 [M] } \\
\text { MHJ0499 [C] } \\
\text { MHJ0498 }[\mathrm{C}]\end{array}$ & $\begin{array}{c}\text { MHP0211 [SB] }^{6} \\
\text { MHP0212 [M] MHP0213 [M] } \\
\text { MHP0214 [C] MHP0215 [C] } \\
\text { MHP0505 [SB] } \\
\text { MHP0504 [M] MHP0503 [M] } \\
\text { MHP0502 [C] MHP0501 [C] }\end{array}$ \\
\hline Metal ions cobalt & $\begin{array}{l}\text { 3.A.1.1 } 8.1 \\
\text { Cobalt uptake }(\mathrm{Co} 2+) \mathrm{im}- \\
\text { porter (homolog to } \mathrm{CbiOQ} \text { of } \\
\text { S. typhimurium) }\end{array}$ & $\begin{array}{c}\text { NF }[\mathrm{SB}] \\
\text { MS0659 [C] MS0660 [C] } \\
\text { MS0034 [C] } \\
\text { MS0661 [M] }\end{array}$ & $\begin{array}{l}\text { NF [SB] } \\
\text { MHJ0255 [C] } \\
\text { MHJ0256 [C] } \\
\text { MHJ0257 [M] }\end{array}$ & $\begin{array}{c}\text { NF }[\mathrm{SB}] \\
\text { MHP0263 [C] } \\
\text { MHP0264 [C] } \\
\text { MHP0265 [M] }\end{array}$ \\
\hline $\begin{array}{l}\text { Phosphonate } \\
\text { Organo-phosphonate } \\
\text { ester }\end{array}$ & $\begin{array}{l}\text { 3.A.1.9.1 } \\
\text { (Phosphonate } \\
\text { /organophosphate ester im- } \\
\text { porter (homolog to PhnCDE } \\
\text { of E. coli) }\end{array}$ & $\begin{array}{l}\mathrm{MS} 0087[\mathrm{SA}]^{4} \\
\mathrm{MS} 0086[\mathrm{C}] \\
\operatorname{MS} 0085[\mathrm{M}]\end{array}$ & $\begin{array}{c}\text { MHJ0356 [SA }]^{4} \\
\text { MHJ0357 [C] } \\
\text { MHJ0358 [M] }\end{array}$ & $\begin{array}{l}\text { MHP0360 [SA }]^{4} \\
\text { MHP0361 [C] } \\
\text { MHP0362 [M] }\end{array}$ \\
\hline $\begin{array}{l}\text { Amine } \\
\text { Polyamine }\end{array}$ & $\begin{array}{l}\text { 3.A.1.11.1 } \\
\text { Polyamine (Putrescine/ } \\
\text { Spermidine) importer (homo- } \\
\text { log to PotABCD of } E \text {. coli) }\end{array}$ & $\begin{array}{c}\text { MS0508 [C] } \\
\text { MS0509 [M] MS0510 [M] } \\
\text { MS0511 [SB] }\end{array}$ & $\begin{array}{c}\text { MHJ0544 [C] } \\
\text { MHJ0543 [M] MHJ0542 [M] } \\
\text { MHJ0541 [SB] }\end{array}$ & $\begin{array}{c}\text { MHP0542 [C] } \\
\text { MHP0541 [M] MHP0540 [M] } \\
\text { MHP0539 [SB] }\end{array}$ \\
\hline
\end{tabular}

${ }^{1}[\mathrm{C}]$ ATP-binding domain; ${ }^{2}[\mathrm{M}]$ Transmembrane domain; ${ }^{3}[\mathrm{SB}]$ Substrate-binding lipoprotein; ${ }^{4}[\mathrm{SA}]$ Surface antigen; ${ }^{5}$ Not found; ${ }^{6}$ Probable ABCassociated substrate-binding lipoprotein.

binding protein of the oligopeptide transporter system, has a surface-localized ATP-binding site which functions as the main ecto-ATPase of the bacteria; although the physiological role of that ATPase activity remains unknown, experiments with oppA-deficient mutants have shown that it might affect cell viability. Similarly, Yoshida et al. (1999) reported that OppA is an important protein for cell growth and viability in E. coli, and its synthesis is stimulated by polyamines at the transcriptional level.
Several reports have demonstrated that polyamines (putrescine, spermidine and spermine) play regulatory roles in cellular growth processes (Tabor and Tabor, 1984; Igarashi and Kashiwagi, 2000; Yoshida et al., 2002). The polyamines are present at millimolar concentrations, and the intracellular concentration is regulated by synthesis, degradation, efflux and uptake (Igarashi and Kashiwagi, 1999). Orthologs of potABCD genes encoding the polyamine uptake system of $E$. coli were found in $M$. 
synoviae strain 53 (MS0508, MS0509, MS0510, MS0511), and in M. hyopneumoniae strains J (MHJ0544, MHJ0543, MHJ0542, MHJ0541) and 7448 (MHP0542, MHP0541, MHP0540, MHP0539). Recently, Yoshida et al. (2004) have demonstrated that the polyamines selectively enhance the expression of a set of genes at the translation level and referred to these genes as a "polyamine modulon", including oppA, cya, rpoS, fecI and fis genes among others.

Metal ions as cobalt are essential for optimal activity of some enzymes, such as the coenzyme $\mathrm{B}_{12}$ and nitrile hydratase (Kobayashi and Shimizu, 1999). Synthesis of enzymes is dependent on a high-affinity uptake of cobalt from the environment, where the nutrient is available in trace amounts only. Cobalt uptake transporters in microorganisms are mediated by secondary transporters and by $\mathrm{ABC}$ transporters (Eitinger et al., 2005). The ABC cobalt transporter CbiOQN of S. typhimurium is well characterized and may be associated with a substrate-binding lipoprotein. A similar complex was found in all three genomes analyzed in this study (Table 2).

Another interesting ABC uptake system annotated in the three mycoplasmas was a phosphonate transporter, which is homolog to PhnCDE of E. coli. A carbon atom covalently bound to phosphorous characterizes phosphonates, which are also found in herbicides organophosphonates, insecticides, and other chemicals. This stable carbon-phosphorous (C-P) bond is resistant to chemical hydrolysis, thermal decomposition, and photolysis, as well as to the action of phosphatases. In E. coli, genes responsible for the C-P lyase pathway were identified ( $p h n$ GHIJKLM) and a model for the utilization of phosphonate was suggested (Yakovleva et al., 1998). CDSs showing homology with the $p h n \mathrm{CDE}$ operon were found in all three strains analyzed in this report (Table 2); however, there was no evidence of genes showing homology to those encoding the enzyme of dephosphonation of phosphonic acids.

\section{Efflux systems}

$\mathrm{ABC}$ export systems in bacteria are also involved in the efflux of substances including surface components of the cell (such as capsular polysaccharides, lipopolysaccharides, and techoic acid), proteins involved in pathogenesis (such as hemolysin, heme-binding protein, and alkalineprotease), peptide antibiotics (bacteriocins), heme, drugs and siderophores (Davidson and Chen, 2004).

The active efflux of antibiotics and other drugs represents a major mechanism developed by microbial species to acquire resistance to the toxicity of these molecules, and the process may be mediated by both drug and multidrug efflux systems (Putman et al., 2000). The drug efflux systems mediate the extrusion of a specific drug or class of drugs, while the multidrug resistance (MDR) systems mediate the extrusion of a variety of structurally unrelated compounds (Putman et al., 2000).
There are few MDR efflux systems characterized in prokaryotes: LmrA in Lactococcus lactis, MsbA in E. coli, HorA in Lactobacillus brevis, VcaM in Vibrio cholerae, and the heterodimeric $\mathrm{ABC}$ transporter EfrAB in Enterococcus faecalis (Raherison et al., 2005). Putative ABC MDR genes were identified in the genomes of both $M$. genitalium and M. pneumoniae (van Veen and Konings, 1998; Paulsen et al., 2000; Raherison et al., 2005), and in $M$. hominis, two MDR ATP-binding cassette transporters were identified ( $m d 1$ and $m d 2$ ) that mediate the active efflux of both ciprofloxacin and ethidium bromide (Raherison et al., 2002, 2005).

Table 3 shows the CDSs related to both drug and multidrug exporter $\mathrm{ABC}$ systems found in the three genomes analyzed in this study, categorized by their substratetype transport. The characterization of these ABC exporter systems can provide a rationale for the use of resistanceblocking agents helpful for the control of bacterial infections.

In M. synoviae and M. hyopneumoniae, specific exporters of the antibiotic sublancin (homologs to SunT of Bacillus subtilis and LagD of Lactococcus lactis) were found. Bacteriocins are extracellular-released bioactivepeptide complexes that have a bactericidal or bacteriostatic effect on other (usually closely related) bacterial species. Also, in the M.synoviae genome two CDSs were found, which show homology to the ABC multidrug/lipid efflux system MsbA of E. coli, and are capable of exporting a variety of antibiotics and lipids.

Interestingly, several CDS homologs to a putative ABC MDR efflux system (Pr1 and Pr2-like) were identified in all three mycoplasma genomes analyzed: six in strain 7448 , five in strain $\mathrm{J}$ and just one in strain 53 . Therefore, the characterization of the substrate associated to these $\mathrm{ABC}$ efflux systems and their gene expression in the pathogenic strains may help to identify new strategies to control bacterial infections.

Also related to efflux systems are the CDSs of a putative heme (homolog to $\mathrm{Ccm} A \mathrm{BC}$ ) group of $\mathrm{ABC}$ exporters. They were found in the genomes of both pathogenic and non-pathogenic strains of $M$. hyopneumoniae. The CcmABC is an ATP-binding cassette encoding a transporter related to the maturation of c-type cytochromes in $E$. coli. The CcmA and $\mathrm{CcmB}$ are probably the subunits of an $\mathrm{ABC}$ exporter; the first is a peripheral membrane protein with a well conserved ATP binding cassette that associates with $\mathrm{CcmB}$, a membrane protein (Meyer, 2002). It is still controversial whether $\mathrm{CcmC}$ is another subunit of the transporter, related to the transport of heme to the periplasm of E. coli, where it is attached to a c-type cytochrome precursor in a post-translational maturation process (Meyer, 2002).

In addition, we found uncharacterized $\mathrm{ABC}$ transporters with several CDSs encoding ATP-binding domains 
Table 3 - Description of the CDSs related to ABC exporters (efflux systems) in the M. synoviae strain 53 (MS) and M. hyopneumoniae strains J (MHJ) and 7448 (MHP) genomes.

\begin{tabular}{|c|c|c|c|c|}
\hline Substrate & TC\# Description & $(\mathrm{MS})$ & $(\mathrm{MHJ})$ & (MHP) \\
\hline Heme group & $\begin{array}{c}\text { 3.A.1.107.1 } \\
\text { Putative heme exporter } \\
\text { (homolog to CcmA of } M \text {. gallisepticum R and E. coli) }\end{array}$ & $\begin{array}{l}\operatorname{MS} 0130[\mathrm{C}]^{1} \\
\operatorname{MS} 0657[\mathrm{C}]\end{array}$ & МHJ0466 [C] & МHР0469 [C] \\
\hline Multidrug & $\begin{array}{l}\text { 3.A.1 - } \\
\text { (Putative MDR efflux system, homolog of Pr1 and } \\
\text { Pr2-like) }\end{array}$ & $\operatorname{MS} 0658[\mathrm{M}]^{2}$ & $\begin{array}{c}\text { MHJ0624 } \\
{[\mathrm{C}-\mathrm{M}]^{3}} \\
\text { MHJ0625 } \\
{[\mathrm{C}-\mathrm{M}]} \\
\text { MHJ0628 } \\
{[\mathrm{C}-\mathrm{M}]} \\
\text { MHJ0629 } \\
{[\mathrm{C}-\mathrm{M}]} \\
\text { MHJ0664 [M] }\end{array}$ & $\begin{array}{c}\text { MHP0623 } \\
{[\mathrm{C}-\mathrm{M}]} \\
\mathrm{MHP} 0624 \\
{[\mathrm{C}-\mathrm{M}]} \\
\mathrm{MHP} 0627 \\
{[\mathrm{C}-\mathrm{M}]} \\
\mathrm{MHP} 0628 \\
{[\mathrm{C}-\mathrm{M}]} \\
\mathrm{MHP} 0664 \\
{[\mathrm{C}-\mathrm{M}]} \\
\mathrm{MHP} 0665 \\
{[\mathrm{C}-\mathrm{M}]} \\
\end{array}$ \\
\hline $\begin{array}{l}\text { Sublancin and } \\
\text { Lactococcin G }\end{array}$ & $\begin{array}{l}\text { 3.A.1.112.4 } \\
\text { Sublancin exporter, SunT } \\
\text { (homolog to SunT of Bacillus subtilis and LagD of } \\
\text { Lactococcus lactis) }\end{array}$ & $\begin{array}{c}\text { MS0391 } \\
{[\mathrm{C}-\mathrm{M}]}\end{array}$ & $\begin{array}{l}\text { MHJ0156 } \\
{[\mathrm{C}-\mathrm{M}]}\end{array}$ & $\begin{array}{l}\text { MHP0160 } \\
{[\mathrm{C}-\mathrm{M}]}\end{array}$ \\
\hline $\begin{array}{l}\text { Phospholipid LPS lipid } \\
\text { A and multidrug }\end{array}$ & $\begin{array}{c}\text { 3.A.1.106.1 } \\
\text { Phospholipid, LPS, Lipid A and drug exporter } \\
\text { (flippase) } \\
\text { (homolog to MsbA of E. coli) }\end{array}$ & $\begin{array}{l}\mathrm{MS} 0513 \\
{[\mathrm{C}-\mathrm{M}]} \\
\mathrm{MS} 0514 \\
{[\mathrm{C}-\mathrm{M}]}\end{array}$ & $\mathrm{NF}^{4}$ & NF \\
\hline
\end{tabular}

${ }^{1}[\mathrm{C}]$ ATP-binding domain; ${ }^{2}[\mathrm{M}]$ Transmembrane domain; ${ }^{3}$ ATP-binding domain fused to transmembrane domain; ${ }^{4}$ Not found.

fused to transmembrane domains, which were exclusively detected in the M. hyopneumoniae genomes (Table 4).

\section{Pathogenicity and $A B C$ transporters}

In relation to the $\mathrm{ABC}$ uptake systems identified in all three sequenced mycoplasma genomes, these were mainly involved in cell nutrition, but some might be indirectly associated with virulence, i.e., $\mathrm{H}_{2} \mathrm{O}_{2}$ production from imported glycerol. In addition, virulence of pathogenic bacteria may also be attributed to the uptake of critical nutrients. Apparently, the number and families of $\mathrm{ABC}$ uptake systems identified in the genomes of the non-pathogenic strain J, of the pathogenic strain 7448 of $M$. hyopneumoniae, and of the pathogenic strain 53 of $M$. synoviae were similar. However, one must consider that there are reports of signature-tagged mutants (STM) in $\mathrm{ABC}$ transporter genes (e.g. opp $\mathrm{C}, o p p \mathrm{D}, o p p \mathrm{~F}$, pot $\mathrm{A}$ and pot $\mathrm{D})$ in Staphylococcus aureus and in Streptococcus pneumoniae that display attenuated virulence phenotypes in animal infection models (Mei et al., 1997; Polissi et al., 1998).

Additionally, the components of $\mathrm{ABC}$ uptake might show immunogenic properties; some substrate-binding proteins, targeted to stimulate specific immune responses, are shown in Table 2. Since mycoplasmas lack a cell wall, the substrate-binding protein (or peripheral proteins) associated to the TMD domain would be the best candidate for a surface antigen. Examples of surface antigens that might be used for the diagnosis of mycoplasma infections are P48 from M. agalactiae (MHJ0606 and MHP0604) (Robino et al., 2005), $\mathrm{P} 46$ from M. hyopneumoniae strain J, which has already been successfully applied to the diagnosis of mycoplasmal pneumonia of swine (MHJ0511) (Futo et al., 1995; Okada et al., 2005), P37 from M. hyorhinis (MS0087, MHJ0356, MHP0360) (Dudler et al., 1988), and P41 from M. fermentans (MS0136) (Calcutt et al., 1999).

Altogether, the findings described here suggest a potential use of these $\mathrm{ABC}$ uptake transporters as targets for novel antimicrobial compounds for pneumonia caused by mycoplasmas of swine and poultry. The successful development of such antimicrobial $\mathrm{ABC}$ transporters would rely on their absence in mammalian cells and also on the knowledge of their structure and molecular modes of action. For example, Smith and Payne (1990) have suggested the use of OppA (oligopeptide-binding protein) in combination with manufactured drugs, in which an antibacterial compound would be linked to the natural substrate (oligopeptide) of this $\mathrm{ABC}$ transporter. In this study we identified some $\mathrm{ABC}$ uptake transporters in pathogenic strains 7448 and 53 that might represent interesting targets for antimicrobial therapies, such as OppA, PotA and PhnC. Furthermore, since some $\mathrm{ABC}$ substrate-binding proteins may be immunogenic, they might also be considered as putative candidates for the development of vaccines..

Protein translocation to the extracellular space is essential for the invasion, colonization, and survival of pathogenic bacteria within a host organism. The $\mathrm{ABC}$ efflux systems are involved in the secretion of a variety of exoproteins including RTX (repeats-in-toxin) toxins, cell surface layer proteins, proteases, lipases, bacteriocins and 
Table 4 - Description of CDSs related to uncharacterized ABC transporter in the M. synoviae strain 53 (MS) and M. hyopneumoniae strains J (MHJ) and 7448 (MHP) genomes

\begin{tabular}{|c|c|c|c|c|}
\hline Substrate & Description & (MS) & (MHJ) & (MHP) \\
\hline Uncharacterized & $\begin{array}{l}\text { ABC transporter with ATP } \\
\text { binding duplicated component } \\
\text { (homolog to } y b i \text { T of } E \text {. coli) }\end{array}$ & $\operatorname{MS} 00802[\mathrm{C}]^{1}$ & MHJ0206 2[C] & MHP0210 2[C] \\
\hline Uncharacterized & $\begin{array}{l}\text { Uncharacterized } \\
\mathrm{ABC} \text { transporter }\end{array}$ & $\begin{array}{l}\mathrm{MS} 0041 \\
{[\mathrm{C}-\mathrm{M}]^{3}}\end{array}$ & $\begin{array}{c}\text { MHJ0333 } \\
{[\mathrm{C}-\mathrm{M}]} \\
\text { MHJ0297 } \\
{[\mathrm{C}-\mathrm{M}]} \\
\text { MHJ0298 } \\
{[\mathrm{C}-\mathrm{M}]} \\
\text { MHJ0018 } \\
{[\mathrm{C}-\mathrm{M}]} \\
\text { MHJ0019 } \\
{[\mathrm{C}-\mathrm{M}]} \\
\text { MHJ0020 } \\
{[\mathrm{C}-\mathrm{M}]}\end{array}$ & $\begin{array}{c}\text { MHP0383 } \\
{[\mathrm{C}-\mathrm{M}]} \\
\text { MHP0340 } \\
{[\mathrm{C}-\mathrm{M}]} \\
\text { MHP0019 } \\
{[\mathrm{C}-\mathrm{M}]} \\
\text { MHP0020 } \\
{[\mathrm{C}-\mathrm{M}]} \\
\text { MHP0021 } \\
{[\mathrm{C}-\mathrm{M}]} \\
\text { MHP0023 } \\
{[\mathrm{C}-\mathrm{M}]} \\
\text { MHP0024 } \\
{[\mathrm{C}-\mathrm{M}]} \\
\text { MHP0314 } \\
{[\mathrm{C}-\mathrm{M}]} \\
\text { MHP0315 } \\
{[\mathrm{C}-\mathrm{M}]}\end{array}$ \\
\hline Uncharacterized & $\begin{array}{c}\mathrm{ABC} \text { transporter, probable anti- } \\
\text { biotic efflux }\end{array}$ & $\begin{array}{l}\operatorname{MS} 0612[\mathrm{C}] \\
\operatorname{MS} 0613[\mathrm{M}]^{2}\end{array}$ & $\begin{array}{l}\text { MHJ0449 [C] } \\
\text { MHJ0450 [M] }\end{array}$ & $\begin{array}{l}\text { MHP0452 [C] } \\
\text { MHP0452 [M] }\end{array}$ \\
\hline
\end{tabular}

${ }^{1}[\mathrm{C}]$ ATP-binding domain; ${ }^{2}[\mathrm{M}]$ Transmembrane domain; ${ }^{3}$ ATP-binding domain fused to transmembrane domain.

lipases (Omori and Idei, 2003). Hence, proteins secreted through $\mathrm{ABC}$ exporters are deeply involved in the pathogenicity of bacteria (Omori and Idei, 2003). In the genome of the three sequenced Mycoplasma, a CDS involved in efflux systems related to the exportation of bacteriocins (such as lactococcin and sublancin) was reported. Also, in the genomes of both pathogenic and non-pathogenic strains of $M$. hyopneumoniae and a pathogenic strain of $M$. synoviae, a set of CDSs related to putative MDR systems was found. However, the efflux systems developed by bacteria may also release toxic compounds and damage the cells (Raherison et al., 2002). One possible mechanism of self-protection would be the removal of the toxic molecules preventing their accumulation in the membrane (Young and Holland, 1999). The MDR transporters may utilize a mechanism of interception of hydrophobic compounds in the bi-layer wall followed by their elimination from the inner leaflet by "flippase" or a "vacuum cleaner" mechanism (Young and Holland, 1999). This is the case for the multidrug/lipid exporter system found in M. synoviae (Table 3).

Finally, ABC efflux systems may be effective as antibacterial targets in the development of inhibitors capable of preventing efflux activity (Li and Nikaido, 2004). Some target candidates are shown in Table 3.

\section{Phylogeny of $\mathrm{ABC}$ transporters}

Using the sequence of one of the first representatives of bacterial ABC transporters, the MalK protein, Saurin et al. (1999) analyzed 197 sequences of putative ABC trans- porters. An unrooted tree displayed two major branches, one grouping the uptake and the other the export system, suggesting that the divergence between these two functionally different types of ABC systems occurred from a common ancestor of living organisms, probably before the divergence of prokaryotes and eukaryotes (Saurin et al., 1999). Clustering of the three protein/domain constituents is similar, therefore each of the three constituents of the $\mathrm{ABC}$ transporters has probably arisen from a common ancestral transporter system with minimal shuffling of constituents between systems. However, today they are functionally diverse and play roles in a wide range of cellular functions (Saier and Paulsen, 2001; Garmory and Titball, 2004).

Ren and Paulsen (2005) have identified 41 transporter families present in all three domains of life, suggesting that they might represent ancient families shared by the last common ancestor. In addition, clustering of the transporters was strongly correlated with phylogenetic profiles, indicating that the types of transporters utilized by organisms are related to their evolutionary history. Throughout the evolutionary process, multicellular organisms have an apparent trend towards specialization, as there are redundant transporter paralogs, while in single-cell organisms there are fewer paralogs but several families of transporters (orthologs), suggesting diversification. One exception in the study of Ren and Paulsen (2005) was the cluster of obligate intracellular pathogens/symbionts, including a group of phylogenetically diverse organisms and Mycoplasma. 
The 14 ATP-binding components of $\mathrm{ABC}$ systems used in this study (Figure 2) reflect the diversity found by Saurin et al. (1999). The most striking feature observed in the phylogenetic tree is that most of the gene families clustered the M. hyopneumoniae strains $\mathrm{J}$ and 7448 , with $M$. synoviae strain 53 as a sister-group. This indicates that $\mathrm{ABC}$ protein family diversity is not the only factor responsible for the pathogenicity of $M$. hyopneumoniae strain

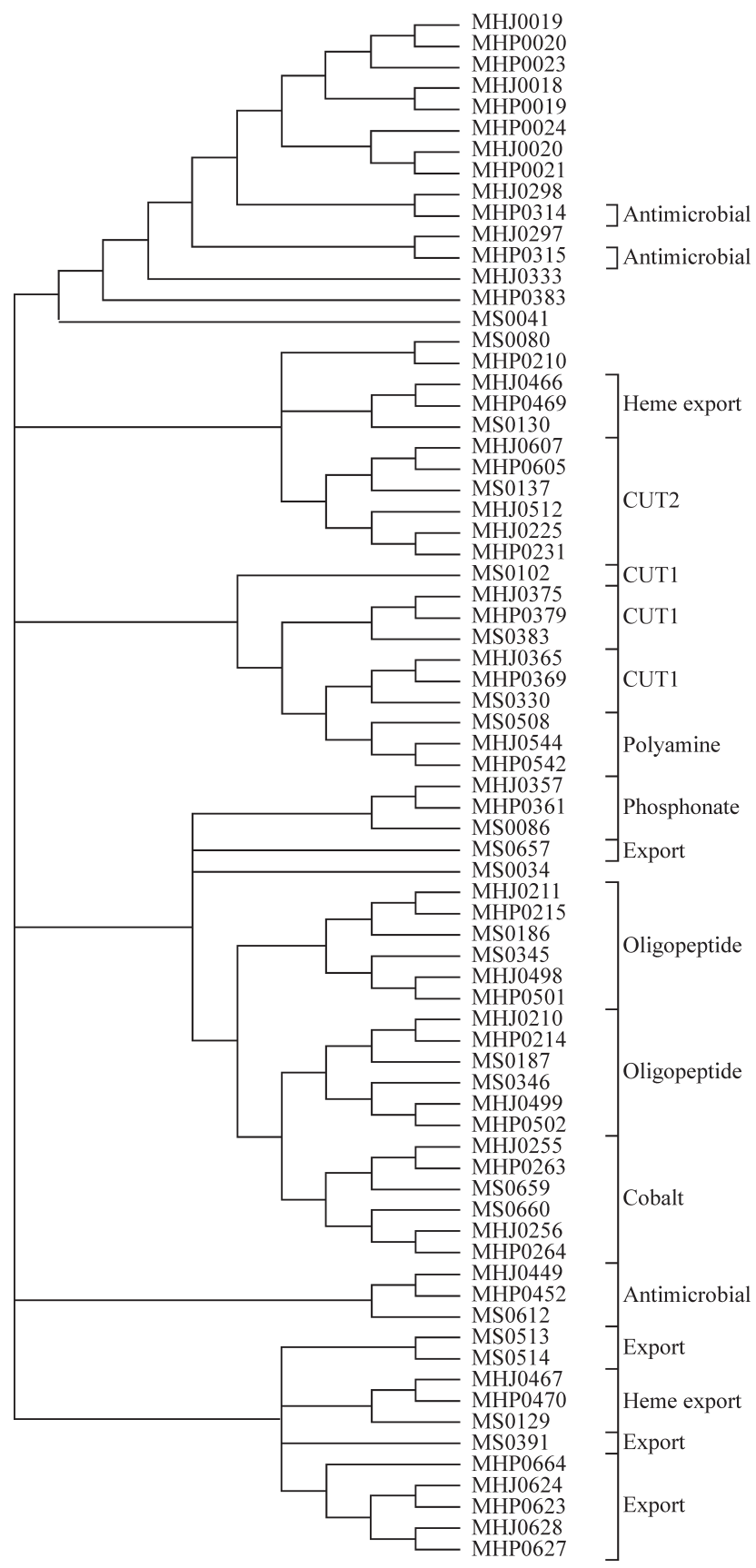

Figure 2 - Phylogenetic tree reconstructed with the nucleotide sequence of ATP-binding domains from the three strains of this study. CUT1 and CUT2: carbohydrate uptake transporters; Export: general or unspecified exporter; Antimicrobial: antibacterial compound exporters; Heme export: Heme compound exporters; Unspecified: undetermined importers; others represent specific elements importers.
7448 and of $M$. synoviae strain 53 . This result is compatible with the hypothesis that virulence in mycoplasmas can be attenuated by successive passage in laboratory media, a process that is mediated by genes encoding adhesin proteins (Collier et al., 1985). This is the case of strain J of $M$. hyopneumoniae, which is a high-passage strain showing a decreased adherence to the host cells and thus unable to induce pneumonia (Zielinski and Ross, 1990; Zielinski et al., 1993).

In conclusion, the analysis of the three genomes of Mycoplasma has not provided major differences in $\mathrm{ABC}$ transporters between pathogenic and non-pathogenic strains; however, several proteins potentially useful as targets for the control of infections were identified.

\section{Acknowledgments}

We would like to thank the Ministério da Ciência e Tecnologia (MCT)/Conselho Nacional de Desenvolvimento Científico e Tecnológico (CNPq), for financial support. F.G. Barcellos and M. Hungria also received fellowships from CNPq.

\section{References}

Braibant M, Gilot P and Content J (2000) The ATP binding cassette (ABC) transport systems of Mycobacterium tuberculosis. FEMS Microbiol Rev 24:449-467.

Calcutt MJ, Kim MF, Karpas AB, Muhlradt PF and Wise KS (1999) Differential posttranslational processing confers intraspecies variation of a major surface lipoprotein and a macrophage-activating lipopeptide of Mycoplasma fermentans. Infect Immun 67:760-771.

Chambaud I, Heilig R, Ferris S, Barbe V, Samson D, Galisson F, Moszer I, Dybvig K, Wroblewski H, Viari A et al. (2001) The complete genome sequence of the murine respiratory pathogen Mycoplasma pulmonis. Nucleic Acids Res 29:2145-2153.

Collier AM, Hu PC and Clyde WA (1985) The changing pathogenicity of Mycoplasma pneumoniae with passage in vitro correlates with virulence. Diagn Microbiol Infect Dis 3:321-328.

Dassa E and Bouige P (2001) The ABC of ABCs: A phylogenetic and functional classification of $\mathrm{ABC}$ systems in living organisms. Res Microbiol 152:211-229.

Davidson AL and Chen J (2004) ATP-binding cassette transporters in bacteria. Annu Rev Biochem 73:241-268.

Detmers FJM, Lanfermeijer FC and Poolman B (2001) Peptides and ATP binding cassette peptide transporters. Res Microbiol 152:245-258.

Dudler R, Schmidhauser C, Parish RW, Wettenhall RE and Schmidt $T$ (1988) A mycoplasma high-affinity transport system and the in vitro invasiveness of mouse sarcoma cells. EMBO J 7:3963-3970.

Eitinger T, Suhr J, Moore L and Smith JA (2005) Secondary transporters for nickel and cobalt ions: Theme and variations. Biometals 18:399-405.

Felsenstein J (1985) Confidence limits on phylogenies: An approach using the bootstrap. Evolution 39:783-791. 
Fraser CM, Gocayne JD, White O, Adams MD, Clayton RA, Fleischmann RD, Bult CJ, Kerlavage AR, Sutton G, Kelley JM et al. (1995) The minimal gene complement of Mycoplasma genitalium. Science 270:397-403.

Futo S, Seto Y, Mitsuse S, Mori Y, Suzuki T and Kawai K (1995) Molecular cloning of a 46-kilodalton surface antigen (P46) gene from Mycoplasma hyopneumoniae: Direct evidence of CGG codon usage for arginine. J Bacteriol 177:1915-1917.

Garmory HS and Titball RW (2004) ATP-binding cassette transporters are targets for the development of antibacterial vaccines and therapies. Infect Immun 72:6757-6763.

Harland DN, Garmory HS, Brown KA and Titball RW (2005) An association between ATP binding cassette systems, genomes sizes and lifestyles of bacteria. Res Microbiol $156: 434-442$

Higgins CF (2001) ABC transporters: Physiology, structure and mechanism -an overview. Res Microbiol 152:205-210.

Himmelreich R, Hilbert H, Plagens H, Pirkl E, Li BC and Herrmann R (1996) Complete sequence analysis of the genome of the bacterium Mycoplasma pneumoniae. Nucleic Acids Res 24:4420-4449.

Holt JG, Krieg NR, Sneath PHA, Staley JT and Williams ST (1994) Berger' s manual of Determinative Bacteriology. Williams, and Wilkins, Baltimore, USA. pp 705-717.

Hopfe M and Henrich B (2004) OppA, the substrate-binding subunit of the oligopeptide permease, is the major Ecto-ATPase of Mycoplasma hominis. J Bacteriol 186:1021-1028.

Hutchison CA III and Montague MG (2002) Mycoplasmas and the minimal genome concept. In Razin S and Herrmann R (eds) Molecular Biology and Pathogenicity of Mycoplasmas. Kluwer Academic/Plenum Publishers, New York, pp 221-253.

Igarashi K and Kashiwagi K (1999) Polyamine transport in bacteria and yeast. Biochem J 344:633-642.

Igarashi K and Kashiwagi K (2000) Polyamines: Mysterious modulators of cellular functions. Biochem Biophys Res Commun 271:559-564.

Jaffe JD, Stange-Thomann N, Smith C, DeCaprio D, Fisher S, Butler J, Calvo S, Elkins T, FitzGerald MG, Hafez N et al. (2004) The complete genome and proteome of Mycoplasma mobile. Genome Res 14:1447-1461.

Jones DT, Taylor WR and Thornton JM (1992) The rapid generation of mutation data matrices from protein sequences. Comput Appl Biosci 8:275-282.

Kobayashi M and Shimizu S (1999) Cobalt proteins. Eur J Biochem 261:1-9.

Kumar S, Tamura K and Nei M (2004) MEGA3: Integrated software for Molecular Evolutionary Genetics Analysis and sequence alignment. Brief Bioinform 5:150-163.

Li XZ and Nikaido H (2004) Efflux-mediated drug resistance in bacteria. Drugs 64:159-204.

Linton KL and Higgins CF (1998) The Escherichia coli ATP binding cassette $(\mathrm{ABC})$ proteins. Mol Microbiol 28:5-13.

McLaughlin RE and Ferretti JJ (1996) The multiple-sugar metabolism ( $\mathrm{msm}$ ) gene cluster of Streptococcus mutans is transcribed as a single operon. FEMS Microbiol Lett 140:261-264.

Mei JM, Nourbakhsh F, Ford CW and Holden DW (1997) Identification of Staphylococcus aureus virulence genes in a murine model of bacteraemia using signature-tagged mutagenesis. Mol Microbiol 26:399-407.
Meyer LT (2002) Cytochrome c maturation: A complex pathway for a simple task? Biochem Soc Trans 30:633-638.

Miles RJ, Taylor RR and Varsani HJ (1991) Oxygen uptake and $\mathrm{H}_{2} \mathrm{O}_{2}$ production by fermentative Mycoplasma spp. J Med Microbiol 34:219-223.

Minion FC, Lefkowitz EJ, Madsen ML, Cleary BJ, Swartzell SM and Mahairas GG (2004) The genome sequence of Mycoplasma hyopneumoniae strain 232, the agent of swine mycoplasmosis. J Bacteriol 186:7123-7133.

Okada M, Asai T, Futo S, Mori Y, Mukai T, Yazawa S, Uto T, Shibata I and Sato S (2005) Serological diagnosis of enzootic pneumonia of swine by a double-sandwich enzyme-linked immunosorbent assay using a monoclonal antibody and recombinant antigen (P46) of Mycoplasma hyopneumoniae. Vet Microbiol 105:251-259.

Omori K and Idei A (2003) Gram-negative bacterial ATP-binding cassette protein exporter family and diverse secretory proteins. J Biosci Bioeng 95:1-12.

Papazisi L, Gorton TS, Kutish G, Markham PF, Browning GF, Nguyen DK, Swartzell S, Madan A, Mahairas G and Geary SJ (2003) The complete genome sequence of the avian pathogen Mycoplasma gallisepticum strain R (low). Microbiology 149:2307-2316.

Paulsen IT, Nguyen L, Sliwinski MK, Rabus R and Saier MHJ (2000) Microbial genome analyses: Comparative transport capabilities in eighteen prokaryotes. J Mol Biol 301:75-100.

Peterson JD, Umayam LA, Dickison T, Hickey EK and White O (2001) The comprehensive microbial resource. Nucleic Acids Res 29:123-125.

Polissi A, Pontiggia A, Feger G, Altieri M, Mottl H, Ferrari L and Simon D (1998) Large-scale identification of virulence genes from Streptococcus pneumoniae. Infect Immun 66:5620-5629.

Putman M, Veen HWV and Konings WN (2000) Molecular properties of bacterial multidrug transporters. Microbiol Mol Biol Rev 64:672-693.

Raherison S, Gonzales P, Renaudin H, Charron A, Bébéar C and Bébéar CM (2002) Evidence of active efflux in resistance to ciprofloxacin and to ethidium bromide by Mycoplasma hominis. Antimicrob Agents Chemother 46:672-679.

Raherison S, Gonzales P, Renaudin H, Charron A, Bébéar C and Bébéar CM (2005) Increased expression of two multidrug transporter-like genes is associated with ethidium bromide and ciprofloxacin resistance in Mycoplasma hominis. Antimicrob Agents Chemother 49:421-424.

Razin S (1985) Molecular biology and genetics of mycoplasmas (Mollicutes). Microbiol Rev 49:419-455.

Razin S (1992) Mycoplasma taxonomy and ecology. In Maniloff J, McElhaney RN, Finch LR and Baseman JB (eds) Mycoplasmas: Molecular Biology and Pathogenesis. American Society for Microbiology, Washington, D.C., USA, pp 3-22.

Razin S, Yogev D and Naot Y (1998) Molecular biology and pathogenicity of mycoplasmas. Microbiol Mol Biol Rev 62:1094-1156.

Ren Q and Paulsen IT (2005) Comparative analysis of fundamental differences in membrane transport capabilities in Prokaryotes and Eukaryotes. PLoS Comput Biol 1:190-201.

Ren Q, Kang KH and Paulsen IT (2004) TransportDB: A relational database of cellular membrane transport systems. Nucleic Acids Res 32:D284-D288. 
Rice P, Houshaymi BM, Abu-Groun EA, Nicholas RA and Miles RJ (2001) Rapid screening of $\mathrm{H}(2) \mathrm{O}(2)$ production by Mycoplasma mycoides and differentiation of European subsp. mycoides SC (small colony) isolates. Vet Microbiol 78:343-351.

Robino P, Alberti A, Pittau M, Chessa B, Miciletta M, Nebbia P, Le Grand D and Rosati S (2005) Genetic and antigenic characterization of the surface lipoprotein P48 of Mycoplasma bovis. Vet Microbiol 109:201-209.

Rocha EP and Blanchard A (2002) Genomic repeats, genome plasticity and the dynamics of Mycoplasma evolution. Nucleic Acids Res 30:2031-2042.

Sahm K, Matuschek M, Muller H, Mitchell WJ and Bahl H (1996) Molecular analysis of the amy gene locus of Thermoanaerobacterium thermosulfurigenes EM1 encoding starch-degrading enzymes and a binding proteindependent maltose transport system. J Bacteriol 178:10391046.

Saier MH Jr (2000) A functional-phylogenetic classification system for transmembrane solute transporters. Microbiol Mol Biol Res 64:354-411.

Saier MH Jr and Paulsen IT (2001) Phylogeny of multidrug transporters. Sem Cell Dev Biol 12:205-213.

Sasaki Y, Ishikawa J, Yamashita A, Oshima K, Kenri T, Furuya K, Yoshino C, Horino A, Shiba T, Sasaki T et al. (2002) The complete genomic sequence of Mycoplasma penetrans, an intracellular bacterial pathogen in humans. Nucleic Acids Res 30:5293-5300.

Saurin W, Hofnung M and Dassa E (1999) Getting in or out: Early segregation between importers and exporters in the evolution of ATP-binding cassette (ABC) transporters. J Mol Evol 48:22-41.

Schneider E and Hunke S (1998) ATP-binding-cassette (ABC) transport systems: Functional and structural aspects of the ATP-hydrolyzing subunits/domains. FEMS Microbiol Rev 22:1-20.

Schneider J (2001) ABC transporters catalyzing carbohydrate uptake. Res Microbiol 152:303-310.

Smith MW and Payne JW (1990) Simultaneous exploitation of different peptide permeases by combinations of synthetic peptide smugglins can lead to enhanced antibacterial activity. FEMS Microbiol Lett 58:311-316.

Tabor CW and Tabor H (1984) Polyamines. Annu Rev Biochem 53:749-790.

Thompson JD, Higgins DG, Gibson TJ (1994) CLUSTAL W: Improving the sensitivity of progressive multiple sequence alignment through sequence weighting, position-specific gap penalties and weight matrix choice. Nucleic Acids Res 22:4673-4680.

Tran CV, Yang NM and Saier MH Jr (2003) TC-DB: An architecture for membrane transport protein analysis. Proceedings of the 2nd International IEEE Computer Society Computational Systems Bioinformatics Conference (CSB 2003), pp 658-659.

van Veen HW and Konings WN (1998) The ABC family of multidrug transporters in microorganisms. Biochim Biophys Acta 1365:31-36.

Vasconcelos AT, Ferreira HB, Bizarro CV, Bonatto SL, Carvalho MO, Pinto PM, Almeida DF, Almeida LG, Almeida R, Alves-Filho L et al. (2005) Swine and poultry pathogens: The complete genome sequences of two strains of
Mycoplasma hyopneumoniae and a strain of Mycoplasma synoviae. J Bacteriol 187:5568-5577.

Vilei EM and Frey J (2001) Genetic and biochemical characterization of glycerol uptake in Mycoplasma mycoides subsp. mycoides SC: Its impact on $\mathrm{H}_{2} \mathrm{O}_{2}$ production and virulence. Clin Diagn Lab Immunol 8:85-92.

Westberg J, Persson A, Holmberg A, Goesmann A, Lundeberg J, Johansson KE, Pettersson B and Uhlen M (2004) The genome sequence of Mycoplasma mycoides subsp. mycoides SC type strain PG1T, the causative agent of contagious bovine pleuropneumonia (CBPP). Genome Res 14:221-2217.

Yakovleva GM, Kim SK and Wanner BL (1998) Phosphateindependent expression of the carbon-phosphorus lyase activity of Escherichia coli. Appl Microbiol Biotechnol 49:573-578.

Yoshida M, Meksuriyen D, Kashiwagi K, Kawai G and Igarashi K (1999) Polyamine stimulation of the synthesis of oligopeptide-binding protein (OppA). Involvement of a structural change of the Shine-Dalgarno sequence and the initiation codon aug in oppa mRNA. J Biol Chem 274:22723-2278.

Yoshida M, Kashiwagi K, Kawai G, Ishihama A and Igarashi K (2002) Polyamines enhance synthesis of the RNA polymerase sigma 38 subunit by suppression of an amber termination codon in the open reading frame. J Biol Chem 277:37139-37146.

Yoshida M, Kashiwagi K, Shigemasa A, Taniguchi S, Yamamoto K, Makinoshima H, Ishihama A and Igarashi K (2004) A unifying model for the role of polyamines in bacterial cell growth, the polyamine modulon. J Biol Chem 279:4600846013.

Young J and Holland IB (1999) ABC transporters: Bacterial exporters-revised five years on. Biochim Biophys Acta 1461:177-200.

Zielinski GC and Ross RF (1990) Effect on growth in cell cultures and strain on virulence of Mycoplasma hyopneumoniae for swine. Am J Vet Res 51:344-348.

Zielinski GC, Young TF and Ross RF (1993) Adherence of Mycoplasma hyopneumoniae to porcine ciliated respiratory tract cells. Am J Vet Res 54:1262-1269.

\section{Internet Resources}

ABCISSE database, http://www.pasteur.fr/recherche/unites/ $\mathrm{pmtg} / \mathrm{abc} /$ database.iphtml (September 10 to 29, 2005).

BRGENE database, http://www.brgene.lncc.br (September 1 to 29, 2005).

GENESUL database, http://www.genesul.lncc.br/ (September 1 to 29,2005$)$.

NCBI database, http://www.ncbi.nlm.nih.gov/ (September 1 to 29, 2005).

Online DAS, http://www.sbc.su.se/ miklos/DAS/ (September 26 to 29,2005$)$.

Online InterProScan, http://www.ebi.ac.uk/InterProScan/ (September 26 to 29,2005$)$.

Online ScanProsite, http://www.expasy.org/tools/scanprosite/ (September 26 to 29, 2005).

Online Tmpred, http://www.ch.embnet.org/software/TMPRED_ form.html (September 26 to 29, 2005).

TC-DB database, http://www.tcdb.org/tcdb/index.php?tc = 3.A.1 (September 10 to 29, 2005).

Associate Editor: Darcy F. de Almeida 